\title{
Intravitreal triamcinolone for the treatment of refractory diabetic macular oedema with hard exudates: an optical coherence tomography study
}

\author{
A P Ciardella, J Klancnik, W Schiff, G Barile, K Langton, S Chang
}

Br J Ophthalmol 2004;88:1131-1136. doi: 10.1136/bjo.2004.041707

Aim: To investigate the use of intravitreal triamcinolone acetonide (IVTA) for the treatment of diabetic macular oedema (DMO) unresponsive to previous laser photocoagulation.

Method: A retrospective, interventional, non-comparative case series. There were 30 eyes of 22 consecutive patients with refractory $\mathrm{DMO}$. An intravitreal injection of triamcinolone acetonide at the dose of $4 \mathrm{mg}$ in $0.1 \mathrm{ml}$ was administered. Best corrected visual acuity was measured at each examination. In addition the central macular thickness was quantitatively measured by optical coherence tomography (OCT) examination at each visit. The amount of hard exudates deposition in the macula was subjectively evaluated using colour fundus photographs.

Results: 30 eyes of 22 patients completed 6 months or more of follow up and were included in the study. Mean (SD) visual acuity improved from $0.17(0.12)$ at baseline to $0.34(0.18)$, $0.36(0.16)$, and $0.31(0.17)$ at the 1,3 , and 6 month follow up respectively. Mean (SD) OCT macular thickness decreased from 476 (98.32) $\mu \mathrm{m}$ at baseline to 277.46 (96.77) $\mu \mathrm{m}, 255.33$ (95.73) $\mu \mathrm{m}$, and 331.25 (146.76) $\mu \mathrm{m}$ at the 1, 3, and 6 month follow up period respectively. 18 and seven eyes completed 12 months and 18 months of follow up, respectively. Mean (SD) visual acuity was 0.36 $(0.15)$ and $0.35(0.16)$ at the 12 and 18 month follow up period respectively. 12 eyes received two, seven eyes received three, and two eyes received four IVTA injections. The mean (SD) interval between the first and second IVTA injection was 5.7 (2.67) months and between the second and third was 5.7 (3.25) months. Hard exudates were present in the macula at baseline in all eyes. Progressive reduction in the number and size of the hard exudates was noted after IVTA in all cases. Intraocular pressure was raised above $21 \mathrm{~mm} \mathrm{Hg}$ in 12 (40\%) of 30 eyes. Two eyes developed posterior subcapsular cataract and two developed vitreous haemorrhage.

Conclusions: IVTA is a promising treatment for patients with DMO refractory to laser treatment. IVTA is effective in improving vision, reducing macular thickness, and inducing reabsorption of hard exudates. Further investigation is warranted to assess the safety of IVTA for the treatment of DMO.

$\mathrm{D}$ iabetic retinopathy is the leading cause of blindness in patients aged 20-74 years in the United States. ${ }^{1}$ Macular oedema affects approximately $29 \%$ of diabetic patients with disease duration of 20 years or more and is the main reason for reduced vision in this population. ${ }^{2}$ In the
Early Treatment Diabetic Retinopathy Study (ETDRS), the 3 year risk of moderate visual loss (a doubling of the initial visual angle or a decrease of three lines or more on a logarithmic visual acuity chart) for diabetic patients with clinically significant macular oedema (CSMO) was 30\%. In the ETDRS study laser photocoagulation reduced the risk of moderate visual acuity loss for all eyes with diabetic macular oedema (DMO) and mild to moderate non-proliferative diabetic retinopathy by about $50 \%{ }^{3}$ However, $12 \%$ of the treated eyes still lost 15 or more ETDRS letters at the 3 year follow up interval. Furthermore, less than $3 \%$ of treated eyes demonstrated an improvement in visual acuity of the same magnitude.

Two different subtypes of DMO are recognised. Focal macular oedema, which is characterised by focal leakage from microaneurysms and is often associated with intraretinal lipid deposition in a circinate pattern; and diffuse macular oedema, which is characterised by diffuse leakage from the retinal capillaries and formation of cystoid spaces. In eyes with diffuse macular oedema, laser treatment cannot be focused on localised leaking microaneurysms, since there is diffuse leakage from the capillary bed and thickening of the entire macula. In the ETDRS, grid laser treatment was applied to areas of diffuse macular oedema. However, previous studies have shown that eyes with diffuse macular oedema carry a particularly poor prognosis despite laser photocoagulation. ${ }^{45}$

Optical coherence tomography (OCT) offers a method of high resolution cross sectional imaging of the retina utilising light to detect relative changes in reflection at optical interfaces. ${ }^{6}$ OCT has proved to be a useful technique for quantifying macular thickness in patients with diabetic macular oedema. ${ }^{7}$

Triamcinolone acetonide (TA) is a corticosteroid suspension that has been used in periocular injections for the treatment of cystoid macular oedema secondary to uveitis and as a result of intraocular surgery. ${ }^{8}$ Intravitreal triamcinolone acetonide (IVTA) has also been used for the treatment of uveitic cystoid macular oedema (CMO), ${ }^{10-12}$ exudative age related macular degeneration, ${ }^{13-16}$ neovascular glaucoma, ${ }^{17} 18$ proliferative diabetic retinopathy, ${ }^{19}$ hypotony, ${ }^{20}$ proliferative vitreoretinopathy, ${ }^{21-24}$ macular oedema secondary to retinal vascular occlusive disease, ${ }^{25-28}$ pseudophakic $\mathrm{CMO}^{29}$ and cystoid macular oedema in retinitis pigmentosa. ${ }^{30}$ IVTA has also been reported to have favourable results in the treatment of diffuse diabetic macular oedema. ${ }^{31-33}$

\footnotetext{
Abbreviations: CSMO, clinically significant macular oedema; CMO, cystoid macular oedema; DMO, diabetic macular oedema; ETDRS, Early Treatment Diabetic Retinopathy Study; IVTA, intravitreal triamcinolone acetonide; OCT, optical coherence tomography; PPV, pars plana vitrectomy; PRP, panretinal photocoagulation; VEGF, vascular endothelial growth factor; $\mathrm{VH}$, vitreous haemorrhage
} 
Given the difficulties of treating patients with diffuse macular oedema unresponsive to laser treatment we decided to evaluate whether the use of IVTA might be effective in reducing macular oedema and improving visual acuity. OCT examination was used to assess quantitative changes in the retinal thickness before and after IVTA.

\section{MATERIALS AND METHODS}

We performed a retrospective chart review of the medical files of consecutive patients diagnosed with CSMO at the Columbia Ophthalmology Consultants practice, in the Edward S Harkness Eye Institute of the New York Presbyterian Hospital, in New York, USA. Thirty eyes of 22 diabetic patients were diagnosed with CSMO according to ETDRS criteria and were treated with IVTA between January 2002 and December 2002. All patients were evaluated and managed by one of three authors (WS, GB, SC). All of the patients were fully informed about the experimental character of the treatment. All of the patients signed an informed consent. In this consecutive series all eyes received at least two previous sessions of laser photocoagulation using ETDRS guidelines; the most recent laser treatment was at least 3 months before IVTA treatment. All eyes considered for IVTA had residual macular thickening on clinical examination with associated visual acuity loss from baseline. The thickening in the fovea measured more than $250 \mu \mathrm{m}$ by OCT. No eyes had history of ocular hypertension or glaucoma.

IVTA was offered to treat residual macular oedema. At baseline all patients received a complete eye examination inclusive of best corrected visual acuity, applanation tonometry, slit lamp examination, lens status evaluation, dilated fundus examination, and biomicroscopy of the posterior pole with a contact lens.

All patients had baseline OCT measurements of the central macular thickness. For each eye the topographic mapping protocol of the OCT software was used (OCT 2000, and Stratus OCT, Carl Zeiss Meditec AG, Jena, Germany). This technique has been previously described, ${ }^{7}$ but briefly at each visit six consecutive linear OCT scans $3.01 \mathrm{~mm}$ in length were obtained at equally spaced angular orientations in a radial spoke pattern centred on fixation. Each of the six tomograms (B-scans) was oriented along a line intersecting the central fovea and contained 100 equally spaced axial profiles (Ascans) of optical reflectivity. Thus, a computer algorithm was used to profile the inner and outer retinal boundaries for each tomogram and retinal thickness was computed automatically

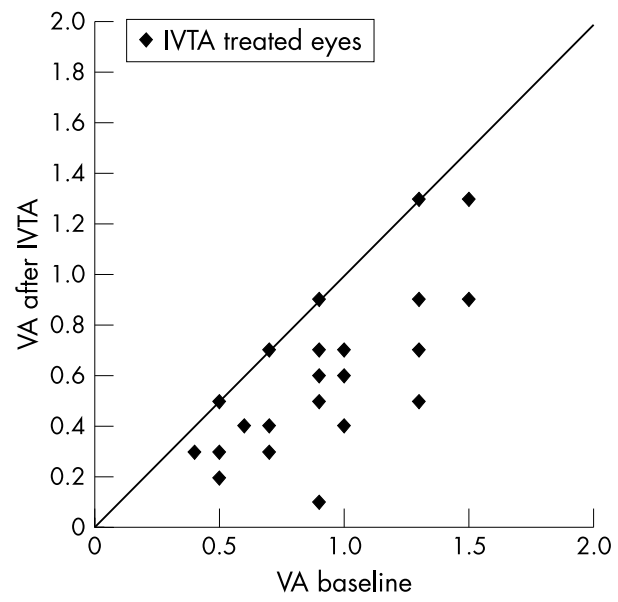

Figure 1 Diagram showing log MAR visual acuity before and 1 month after the first intravitreal injection of $4 \mathrm{mg}$ of triamcinolone acetonide. from these boundaries. The OCT software also rendered a false colour topographic display.

Colour fundus photographs were obtained at baseline and at each follow up visit. Colour fundus photographs were used to evaluate the presence of hard exudates in the macula at baseline and at each follow up visit.

An IVTA injection was performed as here described for all patients. Topical anaesthesia was obtained with tetracaine eye drops, followed by two drops of Ocuflox and 5\% povidone-iodine solution. A cotton tip soaked with tetracaine was then held on the conjunctiva $3.5 \mathrm{~mm}$ inferotemporal to the limbus for 5 minutes. Triamcinolone acetonide (Kenalog 40; Apothecon, Princeton, NJ, USA) was then injected into the vitreous inferotemporally with a 30 gauge needle at a dose of $4 \mathrm{mg}$ in $0.1 \mathrm{ml}$. Indirect ophthalmoscopy was used to confirm intravitreal location of the suspension and perfusion of the optic nerve head.

Patients were instructed to attend for follow up after 1 day, 1 week, 1 month, 3 months, and 6 months. Patients who noticed a worsening of their vision were examined and if necessary re-treated before the scheduled follow up. Further follow up was then scheduled depending on the recurrence of the macular oedema and on the need to repeat the IVTA treatment. OCT examination was performed at baseline and at each follow up visit for all patients. Potential corticosteroid induced and injection related complications were also observed.

\section{RESULTS}

There were eight females and 14 males, for a total of 30 eyes. Mean (SD) age of the patients was 60.41 (11.74) years (median, 62.5 years; range, 37-79 years). Mean (SD) visual acuity was reduced to $0.17(0.12)$ (median, 0.16 ; range $0.032-$ 0.4 ). Mean (SD) intraocular pressure was 16 (2.77) $\mathrm{mm} \mathrm{Hg}$ (median, $16 \mathrm{~mm} \mathrm{Hg}$; range $11-21 \mathrm{~mm} \mathrm{Hg}$ ). Mean (SD) OCT macular thickness at baseline was 476 (98.32) $\mu \mathrm{m}$ (median, $504 \mu \mathrm{m}$; range, $253-669 \mu \mathrm{m})$. Six eyes $(20 \%)$ were pseudophakic for which cataract surgery had been performed at least 6 months before IVTA. The other 24 were phakic. Two eyes $(6 \%)$ had previous pars plana vitrectomy (PPV) surgery for non clearing vitreous haemorrhage $(\mathrm{VH})$ and tractional retinal detachment at least 6 months before IVTA. All 30 eyes completed 6 months of follow up, 18 eyes completed 12 months of follow up and seven eyes completed 18 months of follow up. The mean follow up (SD) for all eyes was 11.7 (5.36) months (median, 12 months; range 6-22 months).

At the 1 month follow up mean (SD) visual acuity improved from $0.17(0.12)$ at baseline of the study to 0.34 (0.18) (median, 0.36; range 0.05-0.8) (fig 1). Mean (SD) OCT

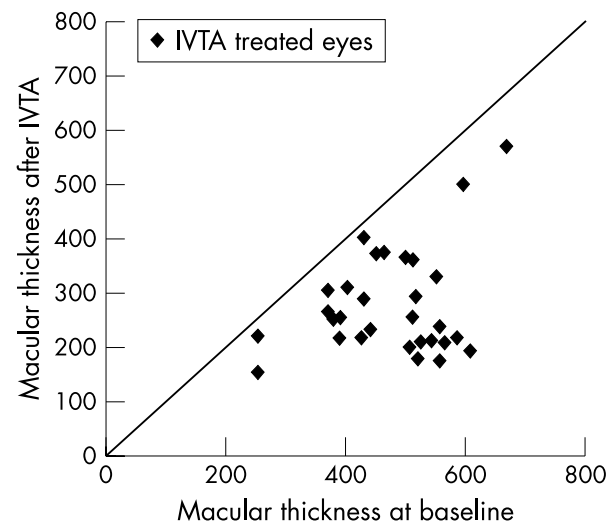

Figure 2 Diagram showing OCT macular thickness before and 1 month after the first intravitreal injection of $4 \mathrm{mg}$ of triamcinolone acetonide. 


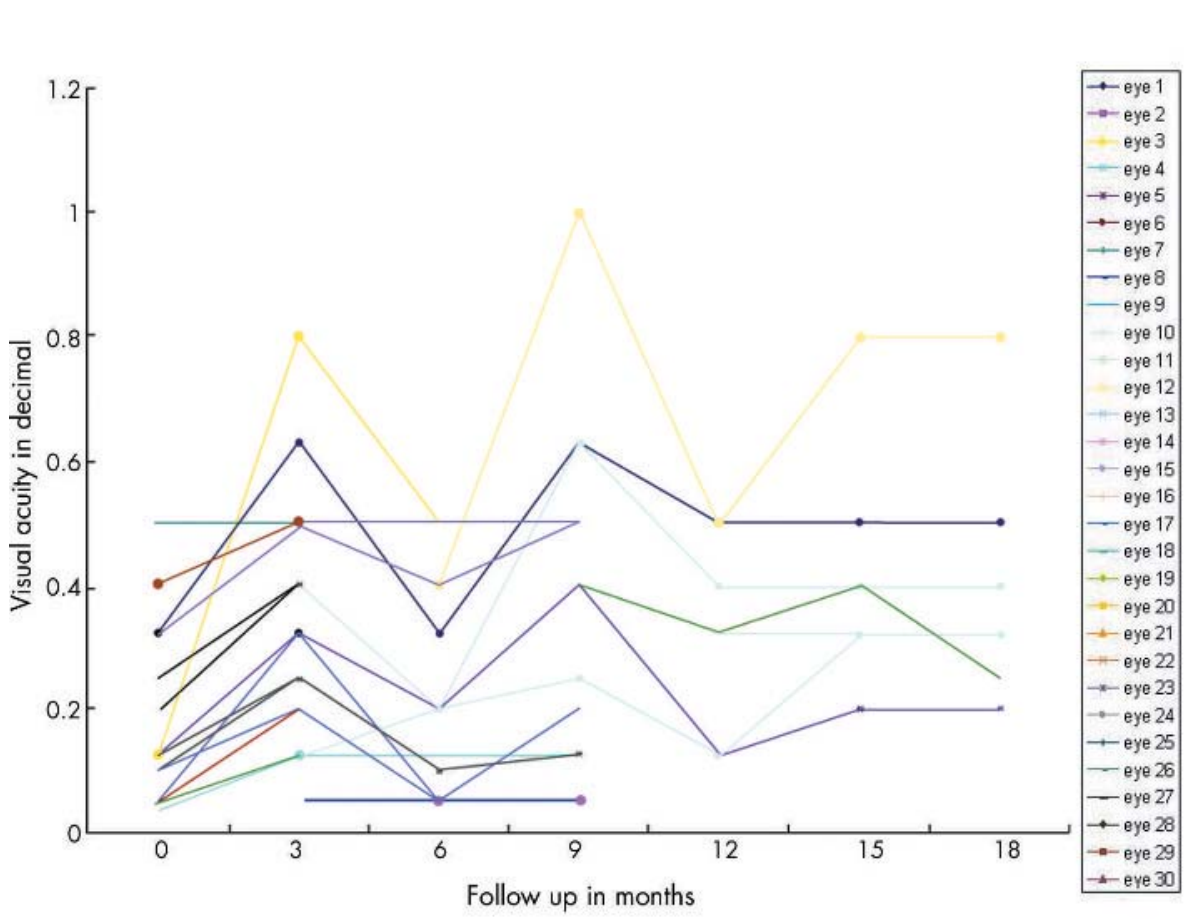

Figure 3 Graphic representation of the change in visual acuity as a function of total follow up time.

macular thickness improved from 476 (98.32) $\mu \mathrm{m}$ at baseline of the study to 277.46 (96.77) $\mu \mathrm{m}$ (median, $251.5 \mu \mathrm{m}$; range $152-570 \mu \mathrm{m}$ ) (fig 2). At the 3 month follow up mean (SD) visual acuity was $0.36(0.16)$ (median 0.37 ; range $0.1-0.8$ ). Mean (SD) OCT macular thickness was 255.33 (95.73) $\mu \mathrm{m}$ (median, $247.86 \mu \mathrm{m}$; range $145-563 \mu \mathrm{m}$ ). At the 6 months follow up mean (SD) visual acuity was 0.31 (0.17) (median 0.32; range 0.05-0.6). Mean (SD) OCT macular thickness was 331.25 (146.76) $\mu \mathrm{m}$ (median $328.54 \mu \mathrm{m}$; range 198-705 $\mu \mathrm{m}$ ). In the first 6 months of follow up eight $(27 \%)$ of 30 eyes experienced a decrease in vision and increase in OCT macular thickness and received a second IVTA injection. Of these eight eyes two received a second IVTA injection 2 months, three eyes 4 months, and three eyes 6 months after the first IVTA injection. Two patients received a second IVTA injection 7 months, one patient 9 months, and one patient 11 months after the first IVTA injection. A total of 12 eyes received two IVTA injections. The mean interval (SD) between the first and second IVTA treatment was 5.7 (2.67) months (median, 6 months; range, 2-11 months). One month after the second IVTA injection the mean (SD) visual acuity improved from 0.27 (0.15) (median; 0.26; range 0.05-0.4) to 0.42 (0.25) (median, 0.4; range 0.05-1.00).

Mean (SD) OCT macular thickness improved from 463.72 (115.80) $\mu \mathrm{m}$ (median, $430 \mu \mathrm{m}$; range $332-685 \mu \mathrm{m}$ ) to 213.33 (63.97) $\mu \mathrm{m}$ (median, $212 \mu \mathrm{m}$; range $147-299 \mu \mathrm{m})$. Of the 18 eyes, which completed 12 months of follow up, seven (38\%) experienced decrease in vision and increase in OCT macular thickness and received a third IVTA injection. Of these seven eyes, one eye received the third IVTA injection 1 month, one eye 3 months, one eye 4 months, one eye 6 months, one eye 7 months, one eye 9 months, and one eye 10 months after the second IVTA injection. The mean (SD) interval between the second and third IVTA treatment was 5.7 (3.25) months (median, 6 months; range 1-10 moths). One month after the third IVTA injection the mean (SD) visual acuity improved from 0.33 (0.15) (median 0.32; range, 0.125-0.5) to 0.42 $(-0.19)$ (median 0.4; range 0.2-0.8). Mean (SD) OCT macular thickness improved from 487.57 (168.85) $\mu \mathrm{m}$ (median, $484 \mu \mathrm{m}$; range $266-792 \mu \mathrm{m}$ ) to 220 (34.30) $\mu \mathrm{m}$ (median, $209 \mu \mathrm{m}$; range $185-268 \mu \mathrm{m}$ ). For all 18 eyes that reached the 12 month follow up mark mean (SD) visual acuity at the 12 month follow up was 0.36 (0.15) (median 0.36; range 0.1-0.8); mean (SD) OCT macular thickness was 267.91 (85.76) $\mu \mathrm{m}$ (median $253.87 \mu \mathrm{m}$; range 177-545 $\mu \mathrm{m}$ ). Of the seven eyes, which completed 18 months of follow up two eyes $(28 \%)$ of the same patient experienced a decrease in visual acuity and increase in OCT macular thickness and required a fourth IVTA injection, one eye 3 months and three eye 4 months after the third IVTA treatment. For these seven eyes at the 18 month follow up mean (SD) visual acuity was 0.35 (0.16) (median 0.36; range 0.1-0.8); mean (SD) OCT macular thickness was 260.55 (85.35) $\mu$ m (median $255.58 \mu \mathrm{m}$; range $163-456 \mu \mathrm{m}$ ). A graphic representation of the change in visual acuity as a function of total follow up time is presented in figure 3.

Hard exudates were present in the macula at baseline in all eyes. Progressive reduction in the number and size of the hard exudates was noted after IVTA in all cases (figs 4 and 5).

During the study period, intraocular pressure was higher than $21 \mathrm{~mm} \mathrm{Hg}$ in 12 of 30 eyes (40\%). In all the eyes, intraocular pressure could be normalised by topical antiglaucomatous medication. Glaucomatous damage to the optic nerve as determined by biomicroscopic examination was not noticed in any eye.

Postoperative infectious endophthalmitis did not occur in any of the study eyes. One patient who received four IVTA injections in both eyes over an 18 month period developed subcapsular cataract reducing the vision in both eyes. One eye underwent uncomplicated cataract surgery. However, no grading of cataract formation in any patients or estimation of the impact of cataract formation on final visual acuity were assessed in this study. Two eyes of two different patients developed VH during the follow up period. In neither case did the occurrence of $\mathrm{VH}$ coincide with the intravitreal injections. One of these two eyes required PPV for non-clearing VH; the other eye received panretinal photocoagulation (PRP) after clearing of the $\mathrm{VH}$. 


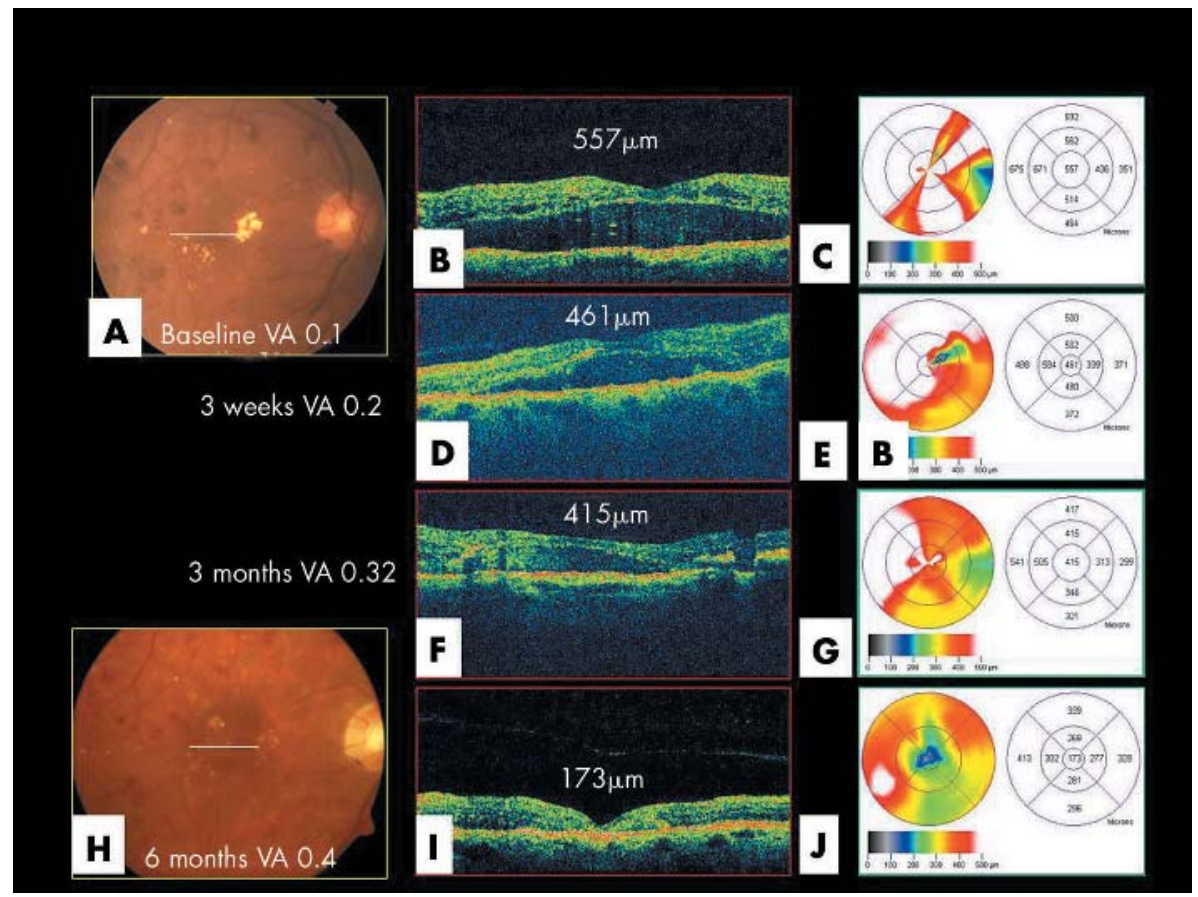

Figure 4 A 69 year old diabetic man with reduced visual acuity in the right eye to the level of 0.1 secondary to diffuse diabetic macular oedema. He had two previous laser treatments in the right eye. Intravitreal triamcinolone acetonide $4 \mathrm{mg}$ in $0.1 \mathrm{ml}$ was injected one time in the right eye. (A) Clinical fundus photograph of the right eye at baseline demonstrated the presence of background diabetic retinopathy. There was diffuse macular oedema, hard exudates, and intraretinal haemorrhages at the posterior pole. The white line represents the area scanned with the OCT. (B) OCT cross section scan through the macula confirmed the presence of macular oedema. There were intraretinal fluid filled cystoid spaces and serous elevation of the neurosensory retina. The macular thickness in the fovea measured by OCT was $557 \mu \mathrm{m}$. (C) False colour topographic map of the macula demonstrated diffuse macular thickening. In the false colour map white corresponds to the area of maximal thickening and blue corresponds to the less thick areas. (D) One month after IVTA the visual acuity had improved to 0.2. The central macular thickness was decreased to $461 \mu \mathrm{m}$. OCT scan through the macula demonstrated slight resolution in the macular oedema. (E) False colour topographic map of the macula demonstrated some reduction in retinal thickness especially in the inferonasal macula. (F) Three months after IVTA visual acuity had improved to 0.32 . There was partial resolution of the serous neurosensory detachment in the macula by OCT. (G) False colour topographic map of the macula confirmed the partial resolution of the macular oedema. There was still thickening temporally (white). (H) Clinical photograph of the same eye 6 months after IVTA revealed resolution of the macular oedema and reduction in the number of hard exudates at the posterior pole. Visual acuity had improved to 0.4 . The white line represents the area scanned with the OCT. (I) OCT scan through the fovea demonstrated almost total resolution of the serous neurosensory macular elevation. There was also disappearance of the intraretinal cystoid spaces. Central macular thickness was $173 \mu \mathrm{m}$. (J) False colour topographic map confirmed the presence of diffuse flattening of the macula.

\section{DISCUSSION}

The use of intravitreal corticosteroid was first advocated by Machemer et al for the treatment of proliferative vitreoretinopathy. ${ }^{21}$ McCuen et al demonstrated in an experimental rabbit model the lack of ocular toxicity of intravitreal triamcinolone acetonide. ${ }^{34}$ Their results were in agreement with clinical observation of cases in which corticosteroids were accidentally injected into the eye, and no major toxic reactions were detected. ${ }^{35}{ }^{36}$ Since then, for decades intravitreal steroids have been used in experimental trials in patients without noticing a significant toxic effect. ${ }^{10-32}$

The exact mechanism of action of corticosteroids in the treatment of macular oedema is unknown. However, the rationale behind their use lies in their ability to inhibit the arachidonic acid pathway, of which prostaglandin is a product. Corticosteroids may also downregulate the production of vascular endothelial growth factor (VEGF). Finally, triamcinolone acetonide has been shown experimentally to

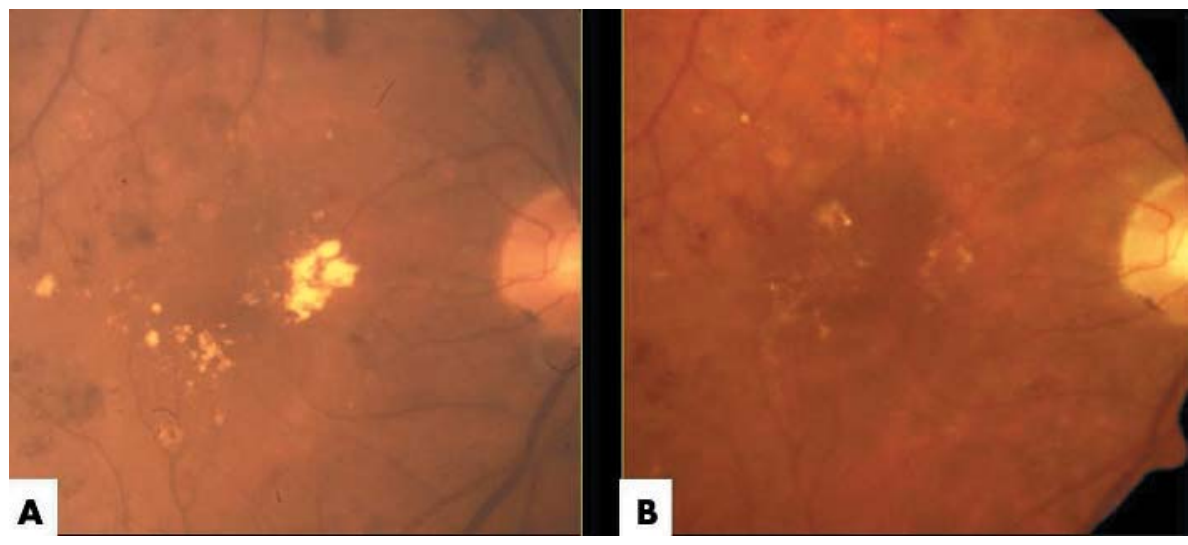

Figure 5 (A) High magnification clinical photograph at baseline of the same patient in figure 3 demonstrated the presence of hard exudates in the macula. (B) High magnification clinical photograph 6 months after IVTA of the same eye revealed marked resolution in the presence of hard exudates in the macula. 
reduce the breakdown of the blood-retinal barrier. ${ }^{37}$ It is accepted that in diabetic macular oedema there is a breakdown of the blood-retina barrier, and that prostaglandins and VEGF may play a part in this process. There is indeed, a theoretic rationale for the use of corticosteroids in the treatment of diabetic macular oedema.

Martidis et al recently reported on the use of IVTA at the dose of $4 \mathrm{mg}$ in $0.1 \mathrm{ml}$ for the treatment of refractory diabetic macular oedema. ${ }^{33}$ Sixteen eyes were enrolled in their study, 14 of the 16 eyes completed 1 month follow up, eight of the 16 eyes $(50 \%)$ completed 6 months follow up. They found a mean improvement in visual acuity of 2.4, 2.4, and 1.3 Snellen lines at the 1, 3, 6 month follow up intervals, respectively. The central macular thickness as measured by OCT decreased by 55\%, 57.5\%, and 38\% respectively, over these same intervals from an initial pretreatment mean (SD) of $540.3(96.3) \mu \mathrm{m}$. Intraocular pressure exceeded $21 \mathrm{~mm} \mathrm{Hg}$ in five, three, and one eye respectively, during these intervals. One eye exhibited cataract progression at 6 months. No other complications were noted over a mean follow up of 6.2 months. Re-injection was performed after 6 months in three of eight eyes $(37 \%)$, because of recurrence of diabetic macular oedema.

Jonas et al reported similar results with the use of IVTA at the dose of $25 \mathrm{mg}$ in $0.2 \mathrm{ml}$ in diabetic patients with diffuse macular oedema. ${ }^{32}$ They enrolled 26 eyes of 20 patients. Mean (SD) follow up was 6.64 (6.10) months. Mean (SD) visual acuity improved from $0.12(0.08)$ at baseline to $0.19(0.14)$ during follow up. One patient received a second intravitreal injection of $25 \mathrm{mg}$ of triamcinolone acetonide. For the 22 patients for whom fluorescein angiograms were available during the pre-injection and post-injection periods, a significant decrease in the fluorescein leakage was noted after IVTA. During the study period intraocular pressure raised above $21 \mathrm{~mm} \mathrm{Hg}$ in nine (34.6\%) of the 26 study eyes.

Both authors concluded that IVTA might be a promising therapeutic method for diabetic macular oedema. These data suggest that IVTA is effective in improving visual acuity and reducing macular thickness measured by OCT. Such a positive effect reaches its maximum 1-3 months after the IVTA treatment. This is followed by a decline in vision and increase in macular thickness over the following months. Repeated IVTA treatment was effective in achieving new improvement in visual acuity. These data are consistent with the work of Beer et al, who showed that in human eyes after intravitreal injection, measurable concentrations of triamcinolone would be expected to last for approximately 3 months (93 (28) days) in a non-vitrectomised eye. ${ }^{38}$

We also noted progressive reabsorption of hard exudates present in the macula over the follow up period. Although reabsorption of hard exudates is expected with reduction in intraretinal vascular leakage and improvement in macular oedema, it has not been reported yet after IVTA. Furthermore, all our patients had long standing macular oedema, and had undergone at least two ETDRS guided laser treatments without improvement in macular oedema and resolution in the lipid exudation.

We did not experience any major complications from IVTA. No case of infectious endophthalmitis occurred in this series. However, infectious and non-infectious endophthalmitis is a potential serious complication of IVTA and careful attention to sterility should be observed during IVTA. ${ }^{39}{ }^{40}$ Intraocular pressure rose above $21 \mathrm{~mm} \mathrm{Hg}$ in $12(40 \%)$ of 30 eyes. These data are slightly higher than in previous studies, which found a rate of increase of intraocular pressure after IVTA for DMO between $31 \%$ and $35 \% .^{32}{ }^{33}$ A possible explanation for this is that the patients in our series had longer follow up and received a higher number of IVTA injections compared with previous studies. In fact, three $(17 \%)$ of 18 eyes that had received only one IVTA injection, four $(80 \%)$ of five eyes who had received two IVTA injections, three $(60 \%)$ of five eyes that had received three IVTA injections, and two (100\%) of two eyes that had received four IVTA injections experienced an IOP $>21 \mathrm{~mm} \mathrm{Hg}$. These data show a pattern for increased risk of rise in IOP with increased number of IVTA injections. If such a risk is confirmed in further studies enrolling a larger number of patients, it could pose a limitation to the use of IVTA for the treatment of DMO. In all cases in this study, the increase in IOP was controlled with topical antiglaucomatous medications. Subcapsular cataract formation is also a reported complication of IVTA. ${ }^{32}$ Two eyes of the same patient demonstrated worsening of cataract in this series; one eye had cataract surgery. Two patients developed VH and one of them required PPV surgery for non-clearing $\mathrm{VH}$. We thought that the occurrence of the $\mathrm{VH}$ was secondary to proliferative diabetic retinopathy and not related to IVTA injection. The occurrence of $\mathrm{VH}$ stresses the importance to carefully follow these patients for any sign of development of neovascularisation of the optic disc and/or elsewhere.

This study has several limitations. It is a retrospective study, it is not randomised, and has no control group. Visual acuity was measured on a Snellen chart, as opposed to the more standardised and accepted ETDRS chart. However, to our knowledge this study has a longer follow up than any published study on the use of IVTA for treatment of DMO. The anatomical data were well documented and quantitative assessment of macular thickness by OCT was available for each follow up visit.

IVTA is a promising therapy for patients with diabetic macular oedema refractory to laser treatment. IVTA is effective in improving vision, reducing macular thickness, and inducing reabsorption of hard exudates. Endophthalmitis is the most serious complication of IVTA, but fortunately did not occur in this study. Further investigation is warranted to assess the efficacy and safety of IVTA for the treatment of refractory diabetic macular oedema.

\section{Authors' affiliations}

A P Ciardella, Denver Health Medical Center, Denver, CO, USA

A P Ciardella, University of Colorado Health Sciences Center, Denver, CO, USA

J Klancnik, W Schiff, G Barile, K Langton, S Chang, Columbia University, New York, NY, USA

None of the authors has any financial interest in the subject matter of the presentation.

Meeting presentation: AAO Annual Meeting November 2003.

Correspondence to: A P Ciardella, MD, Director of Ophthalmology, Denver Health Medical Center, 777 Bannock Street, Mail Code 0156, Denver, CO 80204, USA; Antonio.ciardella@dhha.org

Accepted for publication 19 February 2004

\section{REFERENCES}

1 Chew EY, Ferris III FL. Nonproliferative diabetic retinopathy. In: Ryan SJ, ed. Retina. St Louis: Mosby Inc, 2001:1295-308.

2 Klein R, Klein BEK, Moss SE, et al. The Wisconsin epidemiologic study of diabetic retinopathy. IV. Diabetic macular edema. Ophthalmology 1984;91:1464-74

3 Early Treatment Diabetic Retinopathy Study Research Group. Photocoagulation for diabetic macular edema. Early Treatment Diabetic Retinopathy Study report number 1. Arch Ophthalmol 1985;103:1796-806.

4 Bresnick GH. Diabetic maculopathy: a critical review highlighting diffuse macular edema. Ophthalmology 1983;90:1301-17.

5 Lee CM, Olk RJ. Modified grid laser photocoagulation for diffuse diabetic macular edema: long term visual results. Ophthalmology 1991;98:1594-602.

6 Hee MR, Izatt JA, Swanson EA, et al. Optical coherence tomography of the human retina. Arch Ophthalmol 1995;102:325-32.

7 Hee MR, Puliafito CA, Duker JS, et al. Topography of diabetic macular edema with optical coherence tomography. Ophthalmology 1998;105:360-70. 
8 Riordan-Eva $\mathbf{P}$, Lightman S. Orbital floor steroid injections in the treatment of uveitis. Eye 1994;8:66-9.

9 Stern AL, Taylor DM, Dalburg LA, et al. Pseudophakic cystoid maculopathy: a study of 50 cases. Ophthalmology 1981;88:942-6.

10 Antcliff RJ, Spalton DJ, Stanford MR, et al. Intravitreal triamcinolone for uveitic cystoid macular edema: an optical coherence tomography study. Ophthalmology 2001;108:765-72.

11 Martidis A, Duker JS, Puliafito CA. Intravitreal triamcinolone for refractory cystoid macular edema secondary to birdshot retinochoroidopathy. Arch Ophthalmol 2001;119:1380-3.

12 Young S, Larkin G, Branley M, et al. Safety and efficacy of intravitreal triamcinolone for cystoid macular edema in uveitis. Clin Exp Ophthalmol 2001;29:2-6.

13 Danis RP, Ciulla TA, Pratt LM, et al. Intravitreal triamcinolone acetonide in exudative age related macular degeneration. Retina 2000;20:244-50.

14 Challa JK, Gillies MC, Penfold PL, et al. Exudative macular degeneration and intravitreal triamcinolone: 18 month follow up. Aust N Z J Ophthalmol 1988;26:277-81

15 Jonas JB, Kreissig I, Degenring RF. repeated intravitreal injections of triamcinolone acetonide as treatment of progressive exudative age-related macular degeneration; brief report. Graefes Arch Clin Exp Ophthalmol 2002;240:872-3.

16 Spaide RF, Sorenson J, Maranan L. Combined photodynamic therapy with verteporfin and intravitreal triamcinolone acetonide for choroidal neovascularization. Ophthalmology 2003;110:1517-25.

17 Jonas JB, Hayler JK, Sofker A, et al. Regression of neovascular iris vessels by intravitreal injection of crystalline cortisone. J Glaucoma 2001;10:284-7.

18 Jonas JB, Kreissig I, Degenring RF. Neovascular glaucoma treated by intravitreal triamcinolone acetonide. Acta Ophthalmol Scand 2003:8:540-1.

19 Jonas JB, Hayler JK, Sofker A, et al. Intravitreal injection of crystalline cortisone as adjunctive treatment of proliferative diabetic retinopathy. Am J Ophthalmol 2001;131:468-71.

20 Jonas JB, Hayler JK, Panda-Jonas S. Intravitreal injection of crystalline cortisone as treatment of pre-phthisical ocular hypotony. Graefes Arch Clin Exp Ophthalmol 2001;239:464-5.

21 Machemer R, Sugita G, Tano Y. Treatment of intraocular proliferations with intravitreal steroids. Trans Am Ophthalmol Soc 1979;77:171-80.

22 Tano $Y$, Sugita $G$, Abrams $G$, et al. Inhibition of intraocular proliferation with intravitreal corticosteroid. Am J Ophthalmol 1980;89:131-6.

23 Tano Y, Chandler D, Machemer R. Treatment of intraocular proliferation with intravitreal injection of triamcinolone acetonide. Am J Ophthalmol 1980;90:810-16.
24 Jonas JB, Hayler JK, Panda-Jonas S. Intravitreal injection of crystalline cortisone as adjunctive treatment of proliferative vitreoretinopathy. Br J Ophthalmol 2000;84:1064-7.

25 Greenberg PB, Martidis A, Rogers AH, et al. Intravitreal triamcinolone acetonide for macular oedema due to central retinal vein occlusion. Br J Ophthalmol 2002;86:247-8.

26 Jonas JB, Kreissig I, Degenring RF. Intravitreal triamcinolone acetonide as treatment of macular edema in central retinal vein occlusion. Graefes Arch Clin Exp Ophthalmol 2002;240:782-3.

27 Degenring RF, Kamppeter B, Kreissig I, et al. Morphological and functional changes after intravitreal triamcinolone acetonide for retinal vein occlusion. Acta Ophthalmol Scand 2003;81:548-50.

28 Park CH, Jaffe GJ, Fekrat S. Intravitreal triamcinolone acetonide in eyes with cystoid macular edema associated with central retinal vein occlusion. Am J Ophthalmol 2003;136:419-25.

29 Jonas JB, Kreissig I, Degenring RF. Intravitreal triamcinolone acetonide for pseudophakic cystoid macular edema. Am J Ophthalmol 2003;136:384-6.

30 Saraiva VS, Sallum JM, Farah ME. Treatment of cystoid macular edema related to retinitis pigmentosa with intravitreal triamcinolone acetonide. Ophthalmic Surg Lasers Imaging 2003;34:398-400.

31 Jonas JB, Sofker A. Intraocular injection of crystalline cortisone as adjunctive treatment of diabetic macular edema. Am J Ophthalmol 2001;132:425-7.

32 Jonas JB, Kreissig I, Sofker A, et al. Intravitreal injection of triamcinolone for diffuse diabetic macular edema. Arch Ophthalmol 2003;121:57-61.

33 Martidis A, Duker JS, Greenberg PB, et al. Intravitreal triamcinolone for refractory diabetic macular edema. Ophthalmology 2002; 109:920-7.

34 McCuen BW II, Bessler M, Tano Y, et al. The lack of toxicity of intravitreally administered triamcinolone acetonide. Am J Ophthalmol 1981;91:785-8.

35 Giles CL. Bulbar perforation during periocular injection of corticosteroids. Am J Ophthalmol 1974;77:438-441.

36 McLean EB. Inadvertent injection of corticosteroid into the choroidal vasculature. Am J Ophthalmol 1975;80:835-7.

37 Wilson CA, Berkowitz BA, Sato Y, et al. Treatment with intravitreal steroids reduces blood-retina barrier breakdown due to laser photocoagulation. Arch Ophthalmol 1992;110:155-9.

38 Beer PM, Bakri SJ, Singh RJ, et al. Intraocular concentration and pharmacokinetics of triamcinolone acetonide after a single intravitreal injection. Ophthalmology 2003;110:681-686

39 Roth DB, Chieh J, Spirn MJ, et al. Noninfectious endophthalmitis associated with intravitreal triamcinolone injection. Arch Ophthalmol 2003;121:1279-82.

40 Sutter FK, Gillies MC. Pseudo-endophthalmitis after intravitreal injection of triamcinolone. Br J Ophthalmol 2003;87:972-4. 